\title{
Cost-effectiveness of Chlamydia Vaccination Programs for Young Women
}

\section{Technical Appendix}

\section{Model Equations}

\section{Not Vaccinated}

$$
\begin{aligned}
& \frac{\mathrm{d}}{\mathrm{dt}} \mathrm{S}_{\mathrm{ij}}=-\gamma_{\mathrm{ij}} \mathrm{S}_{\mathrm{ij}}+\mathrm{t}_{\mathrm{i}} \mathrm{qs} \mathrm{s}_{\mathrm{ij}} \mathrm{Is} \mathrm{s}_{\mathrm{ij}}+\left(1-\mathrm{v}_{14 \mathrm{i}}\right) \varphi \mathrm{N}_{\mathrm{ij}}-\varphi \mathrm{S}_{\mathrm{ij}}+\alpha_{\mathrm{i}}\left(\mathrm{Ia}_{\mathrm{ij}}+\mathrm{Is}_{\mathrm{ij}}\right)+\mathrm{nR} \mathrm{ij}_{\mathrm{ij}}+\delta_{\mathrm{i}} \mathrm{Z}_{\mathrm{ij}}-\mathrm{v}_{15-24 \mathrm{i}} \mathrm{S}_{\mathrm{ij}} \\
& \frac{d}{d t} E_{i j}=\gamma_{i j} S_{i j}-\omega E_{i j}-\varphi E_{i j}-v_{15-24 i} E_{i j} \\
& \frac{\mathrm{d}}{\mathrm{dt}} \mathrm{Is}_{\mathrm{ij}}=\xi_{\mathrm{i}} \omega \mathrm{E}_{\mathrm{ij}}-\mathrm{qs} \mathrm{Is}_{\mathrm{ij}}-\varphi \mathrm{Ia}_{\mathrm{ij}}-\alpha_{\mathrm{i}} \mathrm{Is}_{\mathrm{ij}} \\
& \frac{d}{d t} I_{i j}=\omega E_{i j}\left(1-\xi_{i}\right)-q a_{i} I a_{i j}-\varphi I a_{i j}-\alpha_{i} I_{i j}-v_{15-24}{ }_{i} a_{i j} \\
& \frac{\mathrm{d}}{\mathrm{dt}} \mathrm{R}_{\mathrm{ij}}=\left(1-\mathrm{p}_{\mathrm{i}}\right)\left(1-\mathrm{t}_{\mathrm{i}}\right) \mathrm{qs}_{\mathrm{i}} \mathrm{Is}_{\mathrm{ij}}+\left(1-\mathrm{p}_{\mathrm{i}}\right) \mathrm{qa}_{\mathrm{i}} \mathrm{Ia}_{\mathrm{ij}}-\varphi \mathrm{R}_{\mathrm{ij}}-\mathrm{nR} \mathrm{R}_{\mathrm{ij}}-\mathrm{v}_{15-24_{\mathrm{i}}} \mathrm{R}_{\mathrm{ij}} \\
& \frac{d}{d t} Z_{i j}=p_{i}\left(1-t_{i}\right) q s_{i} I_{i j}+p_{i} q a_{i} I_{i j}-\delta_{i} Z_{i j}-\varphi Z_{i j}
\end{aligned}
$$

\section{Vaccinated (Not Effective)}

$$
\begin{aligned}
& \frac{\mathrm{d}}{\mathrm{dt}} \mathrm{S}_{\mathrm{ij}}^{0}=-\gamma_{\mathrm{ij}} \mathrm{S}_{\mathrm{ij}}^{0}+\mathrm{t}_{\mathrm{i}} \mathrm{qs} \mathrm{s}_{\mathrm{i}} \mathrm{Is}_{\mathrm{ij}}^{0}-\varphi \mathrm{S}_{\mathrm{ij}}+\alpha_{\mathrm{i}}\left(\mathrm{Ia}_{\mathrm{ij}}^{0}+\mathrm{Is}_{\mathrm{ij}}^{0}\right)+\mathrm{nR}_{\mathrm{ij}}^{0}+\delta_{\mathrm{i}} \mathrm{Z}_{\mathrm{ij}}^{0}+(1-\mathrm{e}) \mathrm{v}_{15}-24 \mathrm{i} \mathrm{S}_{\mathrm{ij}}+(1-\mathrm{e}) \mathrm{v}_{14 \mathrm{i}} \varphi \mathrm{N}_{\mathrm{ij}}+\mathrm{mS}_{\mathrm{ij}}^{1} \\
& \frac{d}{d t} E_{i j}^{0}=\gamma_{i j} S_{i j}^{0}-\omega E_{i j}^{0}-\varphi E_{i j}^{0}+v_{15-24 i} E_{i j} \\
& \frac{\mathrm{d}}{\mathrm{dt}} \mathrm{Is}_{\mathrm{ij}}^{0}=\xi_{\mathrm{i}} \omega \mathrm{E}_{\mathrm{ij}}^{0}-\mathrm{qs}_{\mathrm{i}} \mathrm{Is}_{\mathrm{ij}}^{0}-\varphi \mathrm{Ia}_{\mathrm{ij}}^{0}-\alpha_{\mathrm{i}} \mathrm{Is}_{\mathrm{ij}}^{0} \\
& \frac{\mathrm{d}}{\mathrm{dt}} \mathrm{Ia} a_{\mathrm{ij}}^{0}=\omega \mathrm{E}_{\mathrm{ij}}^{0}\left(1-\xi_{\mathrm{i}}\right)-\mathrm{qa}{ }_{\mathrm{i}} \mathrm{Ia}_{\mathrm{ij}}^{0}-\varphi \mathrm{Ia} \mathrm{ij}_{\mathrm{ij}}^{0}-\alpha_{\mathrm{i}} \mathrm{Ia}_{\mathrm{ij}}^{0}+\mathrm{v}_{15}-24_{\mathrm{i}} \mathrm{Ia}_{\mathrm{ij}} \\
& \frac{\mathrm{d}}{\mathrm{dt}} \mathrm{R}_{\mathrm{ij}}^{0}=\left(1-\mathrm{p}_{\mathrm{i}}\right)\left(1-\mathrm{t}_{\mathrm{i}}\right) \mathrm{qs}_{\mathrm{i}} \mathrm{Is}_{\mathrm{ij}}^{0}+\left(1-\mathrm{p}_{\mathrm{i}}\right) \mathrm{qa}_{\mathrm{i}} \mathrm{Ia}_{\mathrm{ij}}^{0}-\varphi \mathrm{R}_{\mathrm{ij}}^{0}-\mathrm{nR}_{\mathrm{ij}}^{0}+(1-\mathrm{e}) \mathrm{v}_{15}-24_{\mathrm{i}} \mathrm{R}_{\mathrm{ij}} \\
& \frac{d}{d t} Z_{i j}^{0}=p_{i}\left(1-t_{i}\right) q s_{i} I_{i j}^{0}+p_{i} q a_{i} I_{i j}^{0}-\delta_{i} Z_{i j}^{0}-\varphi Z_{i j}^{0}
\end{aligned}
$$




\section{Vaccinated (Effective)}

$$
\frac{d}{d t} S_{i j}^{1}=e v_{14 i} \varphi N_{i j}+e v_{15-24 i}\left(S_{i j}+R_{i j}\right)-\varphi S_{i j}^{1}-m S_{i j}^{1}
$$

\section{Population Size}

$$
N_{i j}=S_{i j}+E_{i j}+I_{i j}+I_{i j}+R_{i j}+Z_{i j}+S_{i j}^{0}+E_{i j}^{0}+I_{i j}^{0}+I_{i j}^{0}+R_{i j}^{0}+Z_{i j}^{0}+S_{i j}^{1}
$$

\section{Prevalence}

$$
\kappa_{i j}=\frac{I s_{i j}+I a_{i j}+I s_{i j}^{0}+I_{i j}^{0}}{N_{i j}}
$$

\section{Total Infections}

$$
\mathrm{I}_{\mathrm{ij}}=\mathrm{Is} \mathrm{ij}_{\mathrm{ij}}+\mathrm{Ia}_{\mathrm{ij}}+\mathrm{Is}_{\mathrm{ij}}^{0}+\mathrm{Ia}_{\mathrm{ij}}^{0}
$$

\section{Mixing Equation}

$$
\tau_{i j k}=\varepsilon M_{j k}+(1-\varepsilon)\left(\frac{c_{i^{\prime} k} N_{i^{\prime} k}}{\sum_{k} c_{i^{\prime} k} N_{i^{\prime} k}}\right)
$$

\section{Force of Infection}

$\gamma_{i j}=\beta_{i} c_{i j} \sum_{k} \tau_{i j k} \frac{I_{i^{\prime} k}}{N_{i^{\prime} k}}$

Total discounted quality-adjusted life-years (QALYs) =

$$
\int_{y=1}^{50} \frac{1}{\exp ^{\text {ry }}}\left(\text { qaly_ct }_{i} \xi_{i} \omega_{i}\left(E_{i j}^{0}+E_{i j}\right)+\text { qaly_seq }_{i}\left(p_{i}(1-t) q s_{i}\left(I s_{i j}+I_{i j}^{0}\right)+p_{i} q a_{i}\left(I_{i j}+I_{i j}^{0}\right)\right)\right) \bullet d y
$$


Total discounted cost $=$

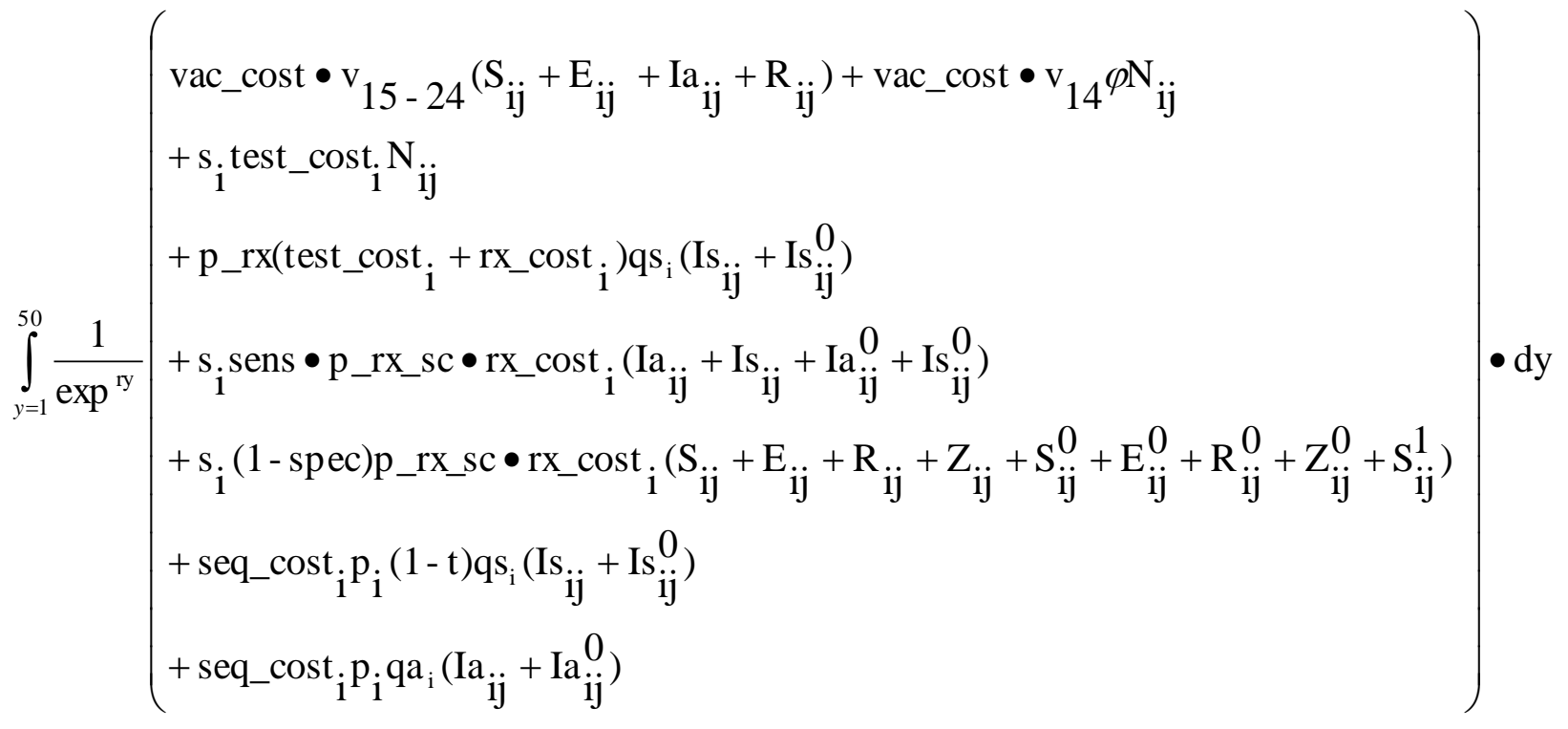

Total discounted infections $=\int_{\mathrm{y}=1}^{50} \frac{1}{\exp ^{\mathrm{ry}}}\left(\omega_{\mathrm{i}}\left(\mathrm{E}_{\mathrm{ij}}^{0}+\mathrm{E}_{\mathrm{ij}}\right)\right) \bullet \mathrm{dy}$

Total discounted sequelae $=\int_{y=1}^{50} \frac{1}{\exp ^{\text {ry }}}\left(p_{i}(1-t) q s_{i}\left(I_{i j}+I_{i j}^{0}\right)+p_{i} q a_{i}\left(I_{i j}+I_{i j}^{0}\right)\right) \bullet d y$

Where S (susceptible), E (exposed), Is (infectious and symptomatic) and Ia (infectious and asymptomatic), R (infection-conferred immunity), and $\mathrm{Z}$ (sequelae) are the 6 compartments representing 6 mutually exclusive health status. Superscripts denote vaccine status and efficacy (none, not vaccinated; 0 , vaccinated and not effective; 1 vaccinated and effective); subscripts $i$, and $j$ represent sex ( $\mathrm{i}=1$ for men, $\mathrm{i}=2$ for women) and sexual activity class ( $\mathrm{j}=1$ for low, $\mathrm{j}=2$ for high), respectively, unless otherwise described. Rate of exit and entry into the population per year is represented by $\varphi$; the recovery rate is represented by $\mathrm{qs}_{\mathrm{q}} \mathrm{qa}_{\mathrm{i}}$ (qs for symptomatic infections; qa for asymptomatic infections); proportion treated successfully is represented by $\mathrm{t}$ (the product of probability of treatment [p_rx/p_rx_sc] and treatment efficacy [rx_success]); $\alpha$ is the annual screen-and-treat coverage, which is the product of the screening rate (s), test sensitivity (sens), postscreening treatment rate (p_rx_sc), and treatment efficacy (rx_sucess); $\mathrm{n}$ and $\mathrm{m}$ are the waning rates for infection-conferred and vaccineconferred immunity, respectively; $\mathrm{p}$ is the probability of sequelae; $\delta$ represents the movement from sequelae to susceptible; e denotes vaccine efficacy; $\mathrm{v}_{14}$ and $\mathrm{v}_{15-24}$ represent vaccine coverage for 14year-old persons and 15-24-year-old persons, respectively; the proportion of symptomatic infections is $\xi$; rate of exit from the exposed state to the infectious states is $\omega$ (for simplicity we assumed the time 
from infection to infectiousness is the same as the time from infection to symptoms); the force of infection $(\gamma)$ is given by the product of the per-partner transmission probability $(\beta)$, the rate of sex partner change (c), and the proportion of sex partners infected: determined by the mixing matrix $\left(\tau_{\mathrm{ijk}}\right.$, where, subscript $\mathrm{k}$ is the sexual activity class of the partner) and the prevalence in the associated sexualactivity classes ( $\kappa)$; opposite subpopulation is differentiated by an apostrophe ('); $\mathrm{M}_{\mathrm{jk}}$ represents full assortative mixing (equals 1 when $\mathrm{j}=\mathrm{k}$ and 0 when $\mathrm{j} \neq \mathrm{k}$ ). Thus, when $\varepsilon=0$, mixing is random and when $\varepsilon=1$, mixing is fully assortative (1). Partnerships were balanced by adjusting the partnership rates using the relationship $c_{11} \mathrm{~N}_{11}=\mathrm{c}_{21} \mathrm{~N}_{21}$ and $\mathrm{c}_{12} \mathrm{~N}_{12}=\mathrm{c}_{22} \mathrm{~N}_{22}$ with the assumption that women made the choice of partnership; partnerships by men were adjusted to equate partnerships by women $(1,2)$. The discount rate is represented by $\mathrm{r}$, y represents year, and exp is the transcendental number (2.71828).

We focused on a hypothetical population 15-24 years of age and assigned the respective lifetime costs and QALYs for each infection (and sequelae) on the basis of the published probabilities. In addition, the duration of immunity (vaccine-conferred and infection-conferred) were applied as rate of movement (inverse of duration) from the respective compartments. Thus, we did not explicitly track the health and economic outcomes (including the duration of vaccine protection) for those persons $>24$ years of age.

\section{Additional Analysis}

The model used for the additional analysis was the same as that used for the main analysis except for a few parameter values. Specifically, we decreased the proportion of women in the low sexual activity group from $97.9 \%$ to $97.6 \%$ and increased the proportion of men in the low sexual activity group from $95.0 \%$ to $95.5 \%$. Essentially, the proportion of women in the high sexual activity group was increased by $0.3 \%$, and the proportion of men in the high sexual activity group was decreased by $0.5 \%$. The value of all other parameters, including costs remained the same as those used for the main analyses.

We used Berkeley Madonna version 8.3.9 (Robert I. Macey and George F. Oster, Berkeley, CA, USA) to solve the system of differential equations. We used an integration fixed time step size of 0.01 year (i.e., $\approx 4$ days) and approximated the system of differential equations by using Runge-Kutta methods. The results were consistent when we repeated the analyses by using a shorter fixed time step of 0.001 year. We used Microsoft Excel version 2010 (Microsoft, Redmond, WA, USA) for creating the Latin hypercube sampling table for the sensitivity and uncertainty analyses. Finally, Stata version 11.1 (StataCorp LP, College Station, TX, USA) was used to conduct the partial rank correlation coefficient analyses. 
Technical Appendix Table. Parameter values, ranges, and symbols/names used in the model of chlamydial vaccination*

\begin{tabular}{|c|c|c|c|}
\hline \multirow[b]{2}{*}{ Parameter } & \multicolumn{2}{|c|}{ Value (range) } & \multirow{2}{*}{$\begin{array}{c}\text { Symbol/parameter } \\
\text { name }\end{array}$} \\
\hline & Men & Women & \\
\hline Duration of symptomatic infection, $d$ & $14(10-21)$ & $28(10-35)$ & $1 / q s$ \\
\hline Duration of asymptomatic infection, $\mathrm{d}$ & $182.5(120-240)$ & $365(240-480)$ & $1 / q a$ \\
\hline Incubation period, d & $14(7-21)$ & $14(7-21)$ & $1 / \omega$ \\
\hline Duration of sequelae, $d$ & $21(10-30)$ & $60(45-75)$ & $1 / \delta$ \\
\hline Probability of sequelae, $\%$ & $2(0-5)$ & $15(10-20)$ & $\mathrm{p}$ \\
\hline Per-partnership transmission probability, \% & $70(25-80)$ & $68(25-80)$ & $\beta$ \\
\hline Probability of symptomatic infection, \% & $50(20-80)$ & $20(10-50)$ & $\xi$ \\
\hline Average no. partners in past year, high sexual activity & $13.30(10.00-16.00)$ & $33.26(30.00-40.00)$ & c \\
\hline Average no. partners in past year, low sexual activity & $0.90(0.60-1.20)$ & $0.88(0.60-1.50)$ & c \\
\hline Proportion in low sexual-activity class, $\%$ & $95.0(90.0-99.0)$ & $97.9(95.0-99.0)$ & p low \\
\hline Annual screening rate, $\%$ & 0 & $30(10-50)$ & $\mathrm{s}$ \\
\hline Probability of postscreening treatment, $\%$ & $80(50-99)$ & $80(50-99)$ & p_rx_sc \\
\hline Probability of treatment, symptomatic, \% & $89(80-100)$ & $89(80-100)$ & $\mathrm{p} \overline{\mathrm{rx}}$ \\
\hline Test sensitivity, \% & $95(90-100)$ & $95(90-100)$ & sens \\
\hline Test specificity, \% & $99(95-100)$ & $99(95-100)$ & spec \\
\hline Treatment efficacy (doxycycline, azithromycin), \% & $92(80-100)$ & $92(80-100)$ & rx_success \\
\hline \multicolumn{4}{|l|}{ QALYs lost/case } \\
\hline Symptomatic infection & $0.005646 \pm 50 \%$ & $0.009913( \pm 50 \%)$ & qaly_ct \\
\hline Sequelaet & $0.009530 \pm 50 \%$ & $0.497580( \pm 50 \%)$ & galy seq \\
\hline \multicolumn{4}{|l|}{ Costs (2013 US Dollars) } \\
\hline Treatment of acute chlamydiał & $185.2 \pm 50 \%$ & $183.0( \pm 50 \%)$ & rx_cost \\
\hline Sequelae† & $1,337 \pm 50 \%$ & $4,516( \pm 50 \%)$ & seq_cost \\
\hline Screening & $55 \pm 50 \%$ & $55( \pm 50 \%)$ & test cost \\
\hline Vaccination & $547 \pm 50 \%$ & $547( \pm 50 \%)$ & vac cost \\
\hline Vaccine coverage, 14 -y-old persons, $\%$ & 0 & $30(10-50)$ & $\bar{v}_{14}$ \\
\hline Vaccine coverage, $15-24$-y-old persons, $\%$ & 0 & 30 & $v_{15-24}$ \\
\hline Vaccine efficacy, \% & $75(50-100)$ & $75(50-100)$ & $\mathrm{E}$ \\
\hline Duration of vaccine-conferred immunity, $y$ & $10(1-100)$ & $10(1-100)$ & $1 / \mathrm{m}$ \\
\hline Duration of infection-conferred immunity, y & $1(0.5-5.0)$ & $1(0.5-5.0)$ & $1 / n$ \\
\hline Relative size of the 14 -y-old population entering model & \multicolumn{2}{|c|}{$10(5-15)$} & $\varphi$ \\
\hline compared with the overall population in model, \% & \multirow{2}{*}{\multicolumn{2}{|c|}{$0.50(0.10-0.90)$}} & \\
\hline Sexual mixing parameter $\$$ & & & $\varepsilon$ \\
\hline Discount rate, $\%$ & \multicolumn{2}{|c|}{$3(0-10)$} & r \\
\hline \multicolumn{4}{|c|}{$\begin{array}{l}\text { *QALYs, quality-adjusted life years. } \\
\text { †Includes productivity costs or QALYs (where applicable) for epididymitis for men and complications associated with pelvic inflammatory diseases (i.e., } \\
\text { chronic pelvic pain, ectopic pregnancy, and infertility) for women. } \\
\text { †Includes productivity costs associated with acute chlamydia and seeking treatment (3) and the reported youth (16-24-y-old persons) employment rate in } \\
2010 \text { ( } 48.9 \% \text { (4). }\end{array}$} \\
\hline
\end{tabular}

\section{References}

1. Garnett GP, Mertz KJ, Finelli L, Levine WC, St Louis ME. The transmission dynamics of gonorrhoea: modelling the reported behaviour of infected patients from Newark, New Jersey. Philos Trans R Soc Lond B Biol Sci. 1999;354:787-97. PubMed http://dx.doi.org/10.1098/rstb.1999.0431

2. Chen MI, Ghani AC, Edmunds WJ. A metapopulation modelling framework for gonorrhoea and other sexually transmitted infections in heterosexual populations. J R Soc Interface. 2009;6:775-91. PubMed

3. Owusu-Edusei K, Roby TM, Chesson HW, Gift TL. Productivity costs of nonviral sexually transmissible infections among patients who miss work to seek medical care: evidence from claims data. Sex Health. 2013;10:434-7. PubMed http://dx.doi.org/10.1071/SH13021

4. Bureau of Labor Statistics. The editor's desk. Youth employment and unemployment in July 2010, 2013 [cited 2013 Sep 15]. http://www.bls.gov/opub/ted/2010/ted_20100903.htm 